\title{
Effect of solvent on the hydration of 2-methylpropene in solutions of p-toluenesulfonic acid and poly(styrenesulfonic acid)
}

Citation for published version (APA):

Meuldijk, J., Joosten, G. E. H., \& Stamhuis, E. J. (1986). Effect of solvent on the hydration of 2-methylpropene in solutions of p-toluenesulfonic acid and poly(styrenesulfonic acid). Journal of Molecular Catalysis, 37(1), 75-92. https://doi.org/10.1016/0304-5102(86)85139-2

DOI:

10.1016/0304-5102(86)85139-2

Document status and date:

Published: 01/01/1986

Document Version:

Publisher's PDF, also known as Version of Record (includes final page, issue and volume numbers)

Please check the document version of this publication:

- A submitted manuscript is the version of the article upon submission and before peer-review. There can be important differences between the submitted version and the official published version of record. People interested in the research are advised to contact the author for the final version of the publication, or visit the $\mathrm{DOI}$ to the publisher's website.

- The final author version and the galley proof are versions of the publication after peer review.

- The final published version features the final layout of the paper including the volume, issue and page numbers.

Link to publication

\footnotetext{
General rights

- You may freely distribute the URL identifying the publication in the public portal. follow below link for the End User Agreement:

www.tue.nl/taverne

Take down policy

If you believe that this document breaches copyright please contact us at:

openaccess@tue.nl

providing details and we will investigate your claim.
}

Copyright and moral rights for the publications made accessible in the public portal are retained by the authors and/or other copyright owners and it is a condition of accessing publications that users recognise and abide by the legal requirements associated with these rights.

- Users may download and print one copy of any publication from the public portal for the purpose of private study or research.

- You may not further distribute the material or use it for any profit-making activity or commercial gain

If the publication is distributed under the terms of Article 25fa of the Dutch Copyright Act, indicated by the "Taverne" license above, please 


\title{
EFFECT OF SOLVENT ON THE HYDRATION OF 2-METHYL- PROPENE IN SOLUTIONS OF $p$-TOLUENESULFONIC ACID AND POLY(STYRENESULFONIC ACID)
}

\author{
JAN MEULDIJK*, GEERT E. H. JOOSTEN** and EIZE J. STAMHUIS \\ Department of Chemical Engineering, The State University of Groningen, Nijenborgh 16 , \\ 9747 AG Groningen (The Netherlands)
}

(Received October 24, 1985; accepted December 11, 1985)

\section{Summary}

Results are reported of a kinetic study on the hydration of 2methylpropene at $25.0{ }^{\circ} \mathrm{C}$ in solutions of $p$-toluenesulfonic acid and poly(styrenesulfonic acid) in mixtures of 1,4-dioxane or sulfolane and water. Both cosolvents have a large influence on the rate of hydration. For sulfolane the rates are higher than for 1,4-dioxane, in spite of the higher solubility of the alkene in 1,4-dioxane/water mixtures.

For the reactions catalyzed by $p$-toluenesulfonic acid, the variation of the pseudo first-order rate constant as a function of the solvent composition is explained in terms of the Hammett acidity function and an examination of the influence of the solvent on the initial- and transition-states of the reaction.

Contrary to the rates of the reactions catalyzed by $p$-toluenesulfonic acid, the rates per equivalent of acid groups are independent of the acid concentration for the reactions catalyzed by poly(styrenesulfonic acid). This is explained by assuming that solutions of poly(styrenesulfonic acid) are divided into an ordered polymer-rich pseudo-phase and a highly disordered pseudo-phase in which the polymer concentration is very low. It appears that for the same overall mol fraction of the cosolvent, the amount of cosolvent in the ordered pseudo-phase is considerably higher for the rather polar sulfolane than for the almost non-polar 1,4-dioxane.

The results of this study will give insight into the influence of the solvent composition on the catalytic activity of sulfonated polystyrene/ divinylbenzene-type cation exchange resins, which are used as catalysts for the hydration of lower alkenes on an industrial scale.

*Author to whom correspondence should be addressed.

**Present address: Nederlandse Gasunie, Groningen. 


\section{Introduction}

In 1972 Deutsche Texaco started the industrial production of 2propanol by the direct hydration of propene, catalyzed by a strong acid ionexchange resin [1,2]. In our laboratory Petrus et al. [3] investigated whether the production of the commercially important 2-butanol can be carried out economically in a similar process by the direct hydration of $n$ butenes. For this purpose the kinetics of the hydration of $n$-butenes in water, catalyzed by a strong acid ion exchange resin, were investigated. The catalyst used was a completely sulfonated copolymer of styrene and divinylbenzene. The results indicate low production rates of 2-butanol per unit of volume of the ion-exchange resin [4]. The main reason for this is the low solubility of the butenes in water. The concentration of the butenes can be considerably increased if an inert organic solvent is added to the reaction mixture. Besides increasing the butene solubility, the presence of the organic cosolvent probably changes the catalytic activity of the acid groups in the ion exchange resin.

In the present study, the influence of the composition of the solvent on the catalytic activity of these acid groups is investigated by measuring the rates of the hydration of 2-methylpropene in solutions of $p$-toluenesulfonic acid or poly(styrenesulfonic acid) in mixtures of 1,4-dioxane and water and in mixtures of sulfolane and water. Furthermore, the influence of the acid concentration on the reaction rate is investigated at some fixed solvent compositions. The hydration of 2-methylpropene was investigated instead of the hydration of the $n$-butenes because of some major experimental advantages of the former reaction over the latter. Firstly, the formation of 2-butanol from the $n$-butenes is accompanied by the isomerization of the linear butenes [3]. This isomerization complicates the kinetics of the hydration of the n-butenes considerably. In the formation of t-butanol from 2-methylpropene, side reactions, like the formation of di-t-butyl ether and dimers of 2-methylpropene, can be neglected [5]. Secondly, the hydration of 2methylpropene shows an appreciable reaction rate, even at room temperature, whereas the hydration of the linear butenes is slow under those conditions.

In the present work special attention is paid to the differences in the influence of $p$-toluenesulfonic acid and poly(styrenesulfonic acid) on the reaction rate and to the differences between the influence of the two cosolvents, 1,4-dioxane and sulfolane, on the reaction rate.

The results collected in this paper give an indication of the extent to which the cosolvents 1,4-dioxane or sulfolane may enhance the rate of hydration of alkenes catalyzed by strong acid ion-exchange resins under practical conditions.

\section{Experimental}

\section{Materials}

2-Methylpropene was obtained from Matheson ( $\geqslant 99 \%$ pure). An aqueous solution of $p$-toluenesulfonic acid (UCB, pure) was prepared by 
dissolving $\sim 90 \mathrm{~g}$ of the monohydrate in $\sim 60 \mathrm{~cm}^{3}$ double-distilled water. The acid concentration of the solution was determined by potentiometric titration using a sodium hydroxide solution. An aqueous solution of poly(styrenesulfonic acid) was prepared by dissolving 25 g sodium poly(styrenesulfonate) (Polysciences, $\mathrm{M}=7 \times 10^{4} \mathrm{~g} \mathrm{~mol}^{-1}$, completely sulfonated) in water. This solution was equilibrated 3 times with an excess of Amberlite IR-120 strong acid ion-exchange resin. The volume of the remaining solution was reduced to $\sim 50 \mathrm{~cm}^{3}$ by evaporation of the solvent. The concentration of the acid groups was determined by potentiometric titration. The sodium content of the solution was less than 0.04\%. 1,4-Dioxane was obtained from Merck (pro-analysi) and was used without further purification. Sulfolane (Shell) was distilled under reduced pressure. The solutions were prepared by mixing accurately weighed amounts of the acid-containing aqueous solution, the organic solvent and double-distilled water. The concentration of acid groups was determined via the density of the solution, which was determined by weighing an accurately known volume of the solution.

\section{Kinetic runs}

The kinetics of the hydration reaction were measured in the apparatus as shown schematically in Fig. 1. The apparatus was constructed of glass.

An accurately weighed amount of the acid-containing solvent was introduced into the cell (1) $\left(V=10^{-4} \mathrm{~m}^{3}\right)$. This cell was connected to a horizontal calibrated tube (2) with a length of $1.5 \mathrm{~m}$ and a volume of $10.4 \times$ $10^{-6} \mathrm{~m}^{3} \mathrm{~m}^{-1}$. Valve (3) allowed disconnection of the cell (1) from the tube (2) for handling of the samples. The cell and the tube were kept at $25.0 \pm$ $0.1{ }^{\circ} \mathrm{C}$ by the water jacket. The tube was connected to a vacuum oil pump via the valves (4) and (5) and to a gas holder via valve (6). A 'drop' of mercury (7) was used as a nearly frictionless piston moving in the calibrated tube. The displacement of the mercury drop as a function of time is related to the rate of absorption of the gas in the solvent. The difference between

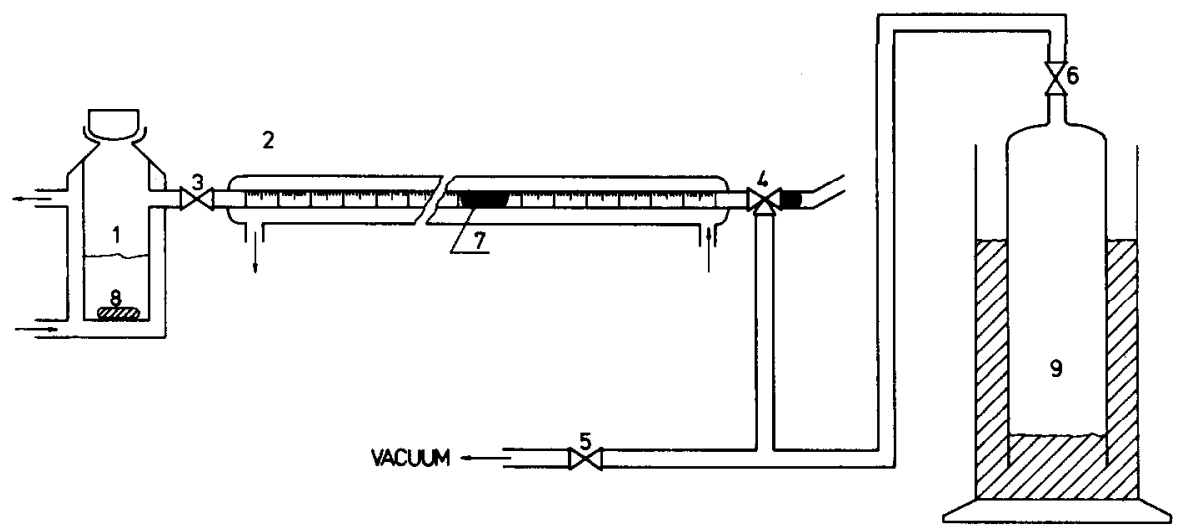

Fig. 1. Schematic representation of the apparatus used for the measurements of the solubilities of alkenes and the reaction rates of the hydration of 2-methylpropene. 
the pressure in the system and the atmospheric pressure was kept less than $10^{2} \mathrm{~Pa}$ by continuously tapping on the glass tube. Before the measurement was started, the system was evacuated under vigorous stirring to remove the air dissolved in the solution. Valve (3) allowed adjustment of the evacuation of the cell (1). The evacuation always lasted less than $\sim 15 \mathrm{~s}$ to avoid significant changes in the solvent composition. After stopping the stirrer (8), valve (5) was closed and the 2-methylpropene gas, stored in gas holder (9), was introduced into the system by opening valve (6). The system was then evacuated for a few seconds and new gas was introduced. This was repeated twice before the mercury drop was introduced into the calibrated tube by opening valve (4). Immediately after introduction, the position of the mercury drop was registered and the stirrer started. For mol fractions of the organic cosolvent greater than $10 \%$, the solution was saturated with the alkene before the mercury drop was introduced into the system. (Before the mercury drop was introduced into the calibrated tube, the pressure in the tube and the cell was lowered to about $90 \%$ of the atmospheric pressure by somewhat raising the gas holder.)

\section{Solubilities}

The measurements of the solubilities of the alkene in solvent mixtures containing less than $10 \mathrm{~mol} \%$ of the organic component were identical to those of the reaction rates in these solvent mixtures, except that no catalyst was present. When the solution was finally saturated with the alkene, the mercury drop had its maximum displacement. The solubility was calculated from the difference between the initial and final positions of the mercury drop, assuming ideal gas behaviour. In solvent mixtures with more than 10 mol\% organic cosolvent, we used a cell with a silicon rubber septum. The empty system was evacuated and the alkene was introduced. A small amount of the solvent mixture (about $0.5 \mathrm{~g}$ ) was brought into the system with a syringe under vigorous stirring. This first amount of solvent was used to bring the system in vapor-liquid equilibrium. After a few minutes the mercury drop was introduced into the calibrated tube. After the saturation of the first amount of solvent another accurately weighed volume of the solvent was introduced. The displacement of the mercury drop was recorded. The maximum displacement, corrected for the sample volume, was used to calculate the solubility.

\section{Results and discussion}

\section{Solubilities}

The solubilities of 2-methylpropene in various mixtures of 1,4-dioxane and water, at $25.0{ }^{\circ} \mathrm{C}$ and a partial pressure of 2-methylpropene of $10^{5} \mathrm{~Pa}$, are collected in Table 1 . In Table 2 the solubilities in mixtures of sulfolane and water are presented.

The results show that the solubility of 2-methylpropene increases sharply with an increasing mol fraction of the organic solvent. For mixtures 
TABLE 1

Solubilities $(S)$ of 2-methylpropene in mixtures of 1,4-dioxane and water at $0.1 \mathrm{MPa}$ partial pressure of 2 -methylpropene and $25.0{ }^{\circ} \mathrm{C}$

\begin{tabular}{lcc}
\hline $\begin{array}{l}\text { Mol fraction 1,4-dioxane } \\
(\%)\end{array}$ & $\begin{array}{l}10^{-1} \mathrm{~S} \\
\left(\mathrm{~mol} \mathrm{~m}_{\mathbf{L}}^{-3}\right)\end{array}$ & $\begin{array}{l}10^{2} \mathrm{~S} \\
\left(\mathrm{~mol} \mathrm{~kg}_{\mathrm{L}}^{-1}\right)\end{array}$ \\
\hline 0 & 0.50 & 0.50 \\
5.0 & 0.95 & 0.94 \\
10.1 & 2.0 & 1.9 \\
19.6 & 6.4 & 6.2 \\
30.3 & 21 & 21 \\
37.0 & 35 & 33 \\
49.7 & 70 & 66 \\
59.7 & 91 & 89 \\
79.8 & 159 & 153 \\
\hline
\end{tabular}

TABLE 2

Solubilities $(S)$ of 2-methylpropene in mixtures of sulfolane and water at $0.1 \mathrm{MPa}$ partial pressure of 2 -methylpropene and $25.0^{\circ} \mathrm{C}$

\begin{tabular}{lll}
\hline $\begin{array}{l}\text { Mol fraction sulfolane } \\
(\%)\end{array}$ & $\begin{array}{l}10^{-1} \mathrm{~S} \\
\left(\mathrm{~mol} \mathrm{~m}_{\mathbf{L}}{ }^{-3}\right)\end{array}$ & $\begin{array}{l}10^{2} \mathrm{~S} \\
\left(\mathrm{~mol} \mathrm{~kg}_{\mathbf{L}}^{-1}\right)\end{array}$ \\
\hline 0 & 0.50 & 0.50 \\
10.0 & 2.0 & 1.8 \\
20.2 & 4.7 & 4.1 \\
29.9 & 7.9 & 6.7 \\
40.0 & 11.7 & 9.7 \\
49.7 & 15.1 & 12.4 \\
60.0 & 19.5 & 15.7 \\
69.6 & 22.5 & 17.9 \\
75.2 & 24.8 & 19.6 \\
89.3 & 28.8 & 22.2 \\
\hline
\end{tabular}

of sulfolane and water, the solubilities are much lower than those in mixtures of 1,4-dioxane and water at the same mol fraction of the cosolvent. This probably originates from the different values of the dielectric constants of both cosolvents, being 2.2 and 43.3 for 1,4-dioxane and sulfolane, respectively.

\section{Rate constants}

The reaction rate, defined per equiv of acid groups, is calculated from the steady state absorption rate, $\phi_{\mathrm{mol}}(\infty)$, according to:

$r_{\mathrm{eq}}=\frac{\phi_{\mathrm{mol}}(\infty)}{\mathrm{CAP}}$ 
Here CAP represents the number of acid groups present in the reaction vessel. It is easily shown that mass transfer resistances between the gas phase and the liquid phase are negligibly small.

The hydration reaction obeys a pseudo first-order rate law:

$r_{\mathrm{eq}}=k$ [alkene]

as derived from mechanistic studies on the acid-catalyzed hydration of alkenes [6,7]. In the absence of mass transfer limitations, the alkene concentration in eqn. (2) is equal to the solubility of the alkene in the reaction mixture. In all experiments, the concentration of the product 2-methyl-2propanol was so small that the reaction may be considered irreversible. This becomes reasonable by the following considerations. The equilibrium constant for the hydration of 2-methylpropene defined in terms of liquid phase concentrations

$K=\left(\frac{\text { [alkanol] }}{\text { [alkene] }}\right)_{\text {chem. eq. }}$

is equal to $1.6 \times 10^{5}$ at $25^{\circ} \mathrm{C}$ and water as solvent (Petrus [5]). In our experiments the concentration of $t$-butanol never exceeded a value of about $2 \times$ $10^{-2} \mathrm{kmol} \mathrm{m}^{-3}$, while at the highest mol fractions of the cosolvent the concentration of the alkene was 1.5 or $0.3 \mathrm{kmol} \mathrm{m}^{-3}$ for 1,4-dioxane or sulfolane, respectively. Even for a dramatic decrease of the equilibrium constant due to the presence of the cosolvent, the reversibility of the reaction may be neglected. This is supported by the fact that the absorption rate of 2-methylpropene during a reaction is independent of time, even at reaction times of several hours.

The rate constants were calculated from the experimentally determined values of $r_{\mathrm{eq}}$ and the solubilities. The solubilities in the solvent mixtures in which the hydration reactions were studied were determined by interpolation of the values collected in Tables 1 and 2 .

The rate constants for $p$-toluenesulfonic acid concentrations of 0.1 $\mathrm{kmol} \mathrm{m}^{-3}$ are collected in Tables 3 and 4 for the cosolvents 1,4-dioxane and sulfolane, respectively.

For mole fractions of the cosolvent between 0 and 0.5 , the rate constant decreases considerably for both cosolvents. For mole fractions above 0.5 , the rate remains constant within experimental accuracy for mixtures of 1,4-dioxane and water and increases continuously for mixtures of sulfolane and water. This behaviour of the rate constant as a function of the solvent composition agrees qualitatively with the variation of the Hammett acidity function, based on substituted anilines, as a function of the mole fraction of the organic solvent in mixtures of 1,4-dioxane and water [8] and in mixtures of sulfolane and water [9]. From this it may be clear that the varying acidity of the catalyst as a function of the solvent composition is at least in part responsible for the behaviour of the rate constant.

Another explanation of the solvent effect on the rate constant may be a dissection of the influence of solvent on the Gibbs free energy of the initial 


\section{TABLE 3}

Reaction rates $\left(r_{\text {eq }}\right)$ and rate constants $(k)$ per equiv of acid groups of the hydration of 2-methylpropene in mixtures of 1,4-dioxane and water, catalyzed by $p$-toluenesulfonic acid at $0.1 \mathrm{MPa}$ partial pressure of 2-methylpropene, an acid concentration of $0.1 \mathrm{kmol}$ $\mathrm{m}^{-3}$ and $25.0^{\circ} \mathrm{C}$

\begin{tabular}{llll}
\hline $\begin{array}{l}\text { Mol fraction 1,4-dioxane } \\
(\%)\end{array}$ & $\begin{array}{l}10^{-1} S^{\mathrm{a}} \\
\left(\mathrm{mol} \mathrm{m}_{\mathrm{L}}{ }^{-3}\right)\end{array}$ & $\begin{array}{l}10^{6} r_{\mathrm{eq}} \\
\left(\mathrm{mol} \mathrm{eq}^{-1} \mathrm{~s}^{-1}\right)\end{array}$ & $\begin{array}{l}10^{8} k \\
\left(\mathrm{~m}_{\mathrm{L}}{ }^{3} \mathrm{eq}^{-1} \mathrm{~s}^{-1}\right)\end{array}$ \\
\hline 0 & 0.50 & 2.24 & 45 \\
5.0 & 0.95 & 1.6 & 17 \\
9.6 & 1.8 & 1.7 & 9.4 \\
15.4 & 3.9 & 1.7 & 4.4 \\
20.5 & 8.0 & 2.0 & 2.5 \\
28.4 & 20 & 2.8 & 1.4 \\
34.5 & 31 & 2.1 & 0.68 \\
39.4 & 42 & 2.5 & 0.60 \\
46.4 & 59 & 2.4 & 0.41 \\
48.8 & 64 & 2.7 & 0.42 \\
59.8 & 93 & 3.7 & 0.40 \\
70.1 & 122 & 4.8 & 0.39 \\
78.9 & 156 & 6.3 & 0.40 \\
\hline
\end{tabular}

a These solubilities are determined graphically with the values collected in Table 1.

TABLE 4

Reaction rates $\left(r_{\text {eq }}\right)$ and rate constants $(k)$ per equiv of acid groups of the hydration of 2-methylpropene in mixtures of sulfolane and water, catalyzed by $p$-toluenesulfonic acid at $0.1 \mathrm{MPa}$ partial pressure of 2-methylpropene, an acid concentration of $0.1 \mathrm{kmol} \mathrm{m}^{-3}$ and $25.0^{\circ} \mathrm{C}$

\begin{tabular}{lllc}
\hline $\begin{array}{l}\text { Mol fraction sulfolane } \\
(\%)\end{array}$ & $\begin{array}{l}10^{-1} S^{\mathrm{a}} \\
\left(\mathrm{mol} \mathrm{m}_{\mathrm{L}}{ }^{-3}\right)\end{array}$ & $\begin{array}{l}10^{6} r_{\mathrm{eq}} \\
\left(\mathrm{mol} \mathrm{eq}^{-1} \mathrm{~s}^{-1}\right)\end{array}$ & $\begin{array}{l}10^{8} k \\
\left(\mathrm{~mL}_{\mathrm{L}} \mathbf{e q}^{-1} \mathrm{~s}^{-1}\right)\end{array}$ \\
\hline 0 & 0.50 & 2.24 & 45 \\
9.5 & 1.9 & 1.94 & 10.2 \\
20.9 & 4.9 & 1.70 & 3.5 \\
31.9 & 8.4 & 1.50 & 1.79 \\
42.8 & 12.6 & 1.84 & 1.46 \\
50.3 & 15.3 & 2.40 & 1.57 \\
59.8 & 19.4 & 3.43 & 1.77 \\
65.4 & 21.3 & 5.55 & 2.61 \\
70.7 & 23.1 & 8.27 & 3.58 \\
74.5 & 24.4 & 9.47 & 3.88 \\
78.1 & 25.5 & 15.6 & 6.11 \\
81.6 & 26.7 & 19.9 & 7.5 \\
83.1 & 27.2 & 27.0 & 9.9 \\
83.8 & 27.4 & 27.7 & 10.1 \\
85.2 & 27.6 & 35.4 & 12.8 \\
87.1 & 28.1 & 49.4 & 17.6 \\
88.3 & 28.5 & 51.6 & 18.1 \\
89.1 & 28.7 & 62.6 & 21.8 \\
\hline
\end{tabular}

a'These solubilities are determined graphically with the values collected in Table 2. 
and transition states of the rate-determining step as described by Abraham [10] and Buncel and Wilson [11]. For this dissection we require values of the transfer chemical potentials of the species involved in the ratedetermining step: formation of the t-butyl carbonium ion [12]. The transfer chemical potentials $\delta_{m} \mu^{\theta}$ of 2-methylpropene in mixtures of 1,4-dioxane and water and sulfolane and water, with water as the reference solvent, were calculated from solubilities:

$\delta_{m} \mu^{\theta}=-R T \ln \frac{S_{x}}{S_{\mathrm{H}_{2} \mathrm{O}}}$

where $S_{x}$ and $S_{\mathrm{H}_{2} \mathrm{O}}$ represent the solubilities in a mixture containing $x$ mol\% 1,4-dioxane or sulfolane and in pure water, respectively. Unfortunately, only transfer Gibbs free energies of the $\mathrm{H}^{+}$ion are available in the literature for dioxane/water mixtures up to $\sim 30 \mathrm{~mol} \%$ dioxane [13], while there are no data available for sulfolane/water mixtures.

For mixtures of 1,4-dioxane and water the transfer chemical potential of the initial state $\left(\delta_{m} \mu^{\theta}\right.$ (IS)) can be calculated by adding the transfer chemical potentials of 2 -methylpropene and the $\mathrm{H}^{+}$ion at the same solvent composition. The transfer chemical potential of the transition state $\left(\delta_{m} \mu^{\ddagger}\right)$ can be calculated according to

$\delta_{m} \mu^{\ddagger}=\delta_{m} \mu^{\theta}(\mathrm{IS})+\delta_{m} \Delta G^{\ddagger}$

where $\delta_{n n} \Delta G^{\ddagger}$ represents the transfer Gibbs free energy of activation.

The latter quantity can be calculated from the rate constants in pure water $\left(k_{\mathrm{H}_{2} \mathrm{O}}\right)$ and in the solvent containing $x$ mol\% organic solvent $\left(k_{x}\right)$ with

$\delta_{m} \Delta G^{\ddagger}=-R T \ln \frac{k_{x}}{k_{\mathrm{H}_{2} \mathrm{O}}}$

In Fig. 2 the transfer chemical potentials of the initial and the transition states in mixtures of 1,4-dioxane and water are plotted as a function of the mol fraction of the cosolvent between 0 and $\sim 35 \mathrm{~mol} \%$ 1,4-dioxane. In Fig. 3 the transfer chemical potentials of 2-methylpropene in mixtures of 1,4-dioxane or sulfolane and water are shown for several solvent compositions. In this Figure the transfer chemical potentials of the $\mathrm{H}^{+}$ion in mixtures of 1,4-dioxane and water, as determined by Wells [13], are also plotted as a function of the solvent composition.

Figure 2 shows that for mixtures of 1,4-dioxane and water, the lowest value of the transfer chemical potential of the transition state is found at $\sim 16 \mathrm{~mol} \%$ 1,4-dioxane. This minimum and the minimum in the plot of the transfer chemical potentials of the $\mathrm{H}^{+}$ion as a function of the mol fraction of 1,4-dioxane (Fig. 3) are positioned at about the same solvent composition. From the variation of the transfer chemical potentials of the initial and transition states as a function of the mol fraction of 1,4-dioxane, it seems reasonable that the large stabilization of the initial state is at least in part responsible for the decrease of the rate constant with increasing 1,4-dioxane content of the reaction mixture. The stabilization of the initial state 

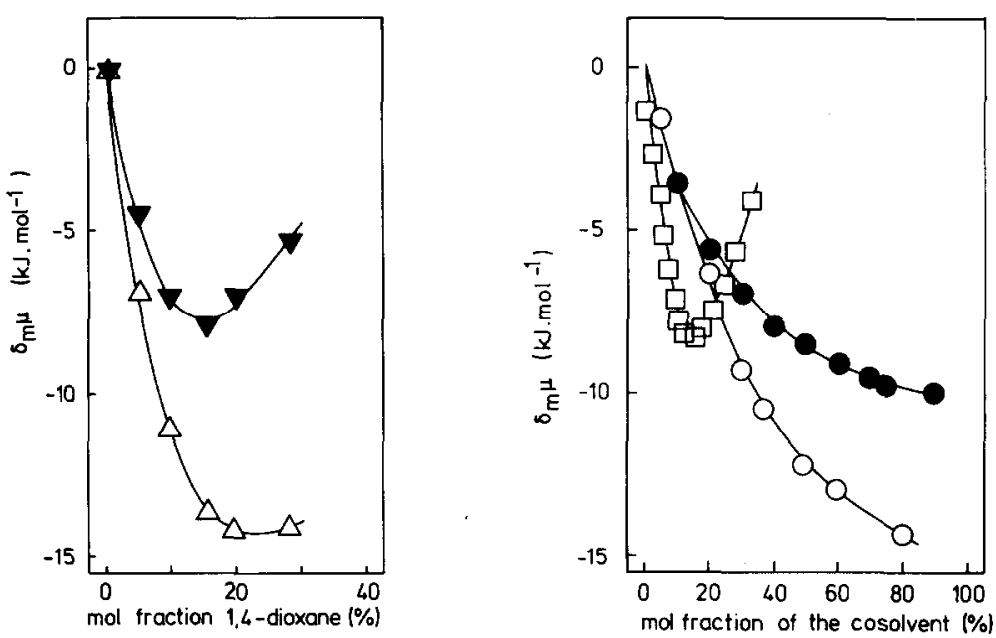

Fig. 2. Transfer chemical potentials $\left(\delta_{m} \mu\right)$ of the initial $(\Delta)$ and transition states $(\nabla)$ of the hydration of 2-methylpropene in mixtures of 1,4-dioxane and water at $25.0^{\circ} \mathrm{C}$. The reference solvent is water.

Fig. 3. Transfer chemical potentials $\left(\delta_{m} \mu\right)$ of 2-methylpropene in mixtures of 1,4-dioxane and water $(O)$ and in mixtures of sulfolane and water $(\bullet)$ and transfer chemical potentials of the $\mathrm{H}^{+}$ion in mixtures of 1,4 -dioxane and water $(\square)[13]$ at $25.0{ }^{\circ} \mathrm{C}$. The reference solvent is water.

originates mainly from the solvent effect on the chemical potential of 2 methylpropene.

In mixtures of sulfolane and water, the stabilization of 2-methylpropene is much smaller than in mixtures of dioxane and water, while the rate constants in mixtures of sulfolane and water are considerably larger than those in mixtures of 1,4-dioxane and water. This is also an indication that the influence of solvent on the initial state plays an important role in the medium effects on the rate constant of the hydration of alkenes.

The influence of the concentration of $p$-toluenesulfonic acid on the rate constant of the hydration reaction was investigated in water, in two mixtures of 1,4-dioxane and water and in two mixtures of sulfolane and water. The results are illustrated in Figure 4 . These results show that in water and in mixtures of sulfolane and water, the catalytic activity per equiv of acid groups increases with increasing concentration of acid groups in the reaction mixture. This influence of the acid concentration on the rate constant was also found by Taft [14], who investigated the hydration of 2-methylpropene in water catalyzed by nitric acid. If we want to compare our results in water with those of Taft, we need pseudo-first-order rate constants calculated from the reaction rate per unit volume of the reaction mixture $\left(r_{v}\right)$. The value of $r_{v}$ is calculated from the steady state absorption rate of the alkene $\phi_{\text {mol }}(\infty)$ with

$r_{\mathrm{v}}=\frac{\phi_{\mathrm{mol}}(\infty)}{V}\left(\mathrm{~mol} \mathrm{~m}_{\mathrm{L}}^{-3} \mathrm{~s}^{-1}\right)$ 


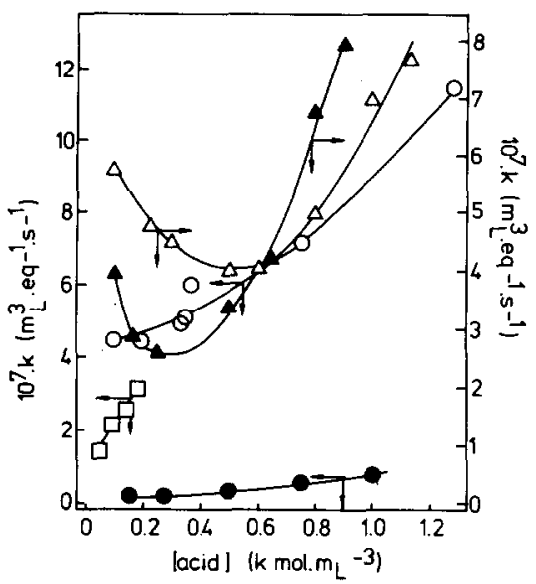

Fig. 4. Reaction rate constants per equiv of acid groups of the hydration of 2-methylpropene, catalyzed by $p$-toluenesulfonic acid at $25.0{ }^{\circ} \mathrm{C}$, as a function of the acid concentration. $O$ : water; $: 49.0 \mathrm{~mol} \%$ sulfolane; $\square$ : $89.1 \mathrm{~mol} \%$ sulfolane; $\triangle: 39.4 \mathrm{~mol} \%$ 1,4-dioxane; $4: 59.8 \mathrm{~mol} \%$ 1,4-dioxane.

TABLE 5

Reaction rates $\left(r_{v}\right)$ and rate constants $\left(k^{*}\right)$ per unit of volume of the reaction mixture of the hydration of 2-methylpropene in water at $0.1 \mathrm{MPa}$ partial pressure of 2-methylpropene, $25.0^{\circ} \mathrm{C}$ and several concentrations of $p$-toluenesulfonic acid

\begin{tabular}{lll}
\hline $\begin{array}{l}\text { Acid] } \\
\left(\mathrm{kmol} \mathrm{m}_{\mathrm{L}}^{-3}\right)\end{array}$ & $\begin{array}{l}10^{3} r_{\mathrm{v}} \\
\left(\mathrm{mol} \mathrm{m}_{\mathrm{L}}^{-3} \mathrm{~s}^{-1}\right)\end{array}$ & $\begin{array}{l}10^{4} k^{*} \\
\left(\mathrm{~s}^{-1}\right)\end{array}$ \\
\hline 0.100 & 0.224 & 0.45 \\
0.200 & 0.45 & 0.90 \\
0.333 & 0.81 & 1.62 \\
0.345 & 0.88 & 1.76 \\
0.366 & 1.08 & 2.16 \\
0.750 & 2.7 & 5.4 \\
1.28 & 7.3 & 14.6 \\
\hline
\end{tabular}

where $V$ is the volume of the reaction mixture. The pseudo-first-order rate constant $k^{*}$ in units $\mathrm{s}^{-1}$ is derived from $r_{\mathrm{v}}$ with

$r_{\mathrm{v}}=k^{*}$ [alkene]

The values of $k^{*}$ in water as a function of the concentration of $p$-toluenesulfonic acid are collected in Table 5.

In Fig. $5, \log _{10} k^{*}$ is plotted as a function of the values of the Hammett acidity function $H_{0}$ in aqueous solutions of $p$-toluenesulfonic acid. These $H_{0}$ values are based on tertiary amines and were determined by Arnett and Mach [15]. Contrary to the results of Taft [14], our measurements show a considerable deviation from linearity between $\log _{10} k^{*}$ and $H_{0}$. Arnett and Mach [15] showed that this deviation from linearity often can be described by a 

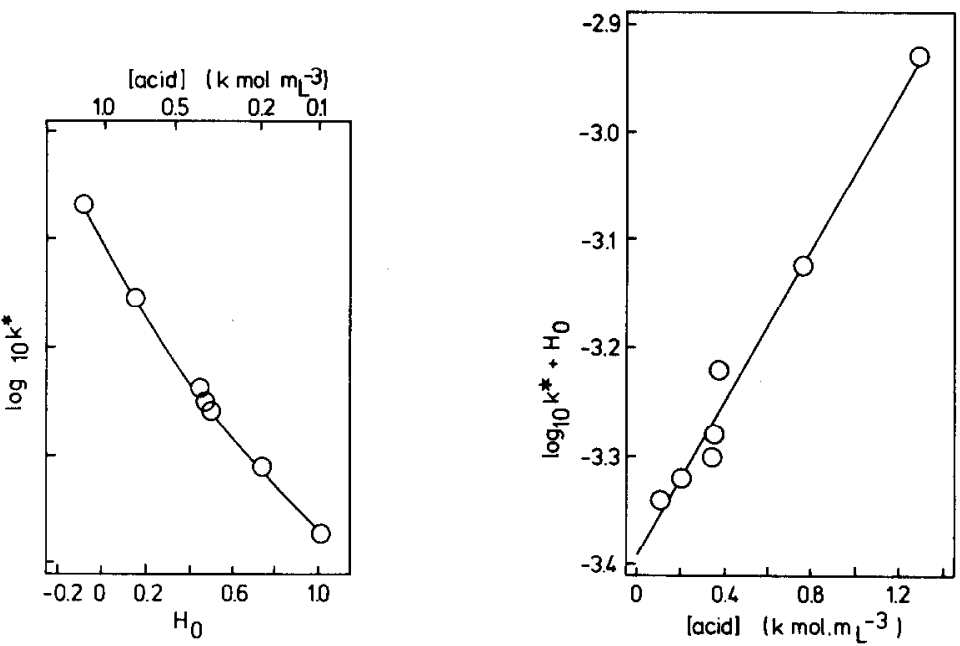

Fig. 5. Reaction rate constants $\left(k^{*}\right)$ calculated from the rates of the hydration of 2methylpropene per unit of volume at $25.0{ }^{\circ} \mathrm{C}$ and catalyzed by $p$-toluenesulfonic acid as a function of the Hammett acidity function $\left(H_{0}\right)$ based on tertiary amines [15].

Fig. 6. Sum of the Hammett acidity functions based on tertiary amines $\left(H_{0}\right)[15]$ and the logarithm of the rate constant calculated from the reaction rates of the hydration of 2methylpropene per unit volume at $25.0^{\circ} \mathrm{C}$ as a function of the $p$-toluenesulfonic acid concentration.

term proportional to the acid concentration. This leads to the following relationship:

$\log _{10} k^{*}+H_{0}=A[$ acid $]+$ constant

where $A$ is a proportionality constant.

From Fig. 6, where $\log _{10} k^{*}+H_{0}$ is plotted against the acid concentration, it can be concluded that our results in water follow eqn. (10). The different behaviour of nitric acid and $p$-toluenesulfonic acid can be explained by means of a relation where the failure of the $\log _{10} k^{*}$ to correlate with $H_{0}$ is written in terms of an activity coefficient ratio [16]:

$\log _{10} k^{*}=-H_{0}+\log _{10} \frac{f_{\text {alkene }} f_{\mathrm{BH}^{+}}}{f_{\neq} f_{\mathrm{B}}}+$ constant

where $f_{\text {alkene }}, f_{\neq}, f_{\mathrm{B}}$ and $f_{\mathrm{BH}^{+}}$are the activity coefficients of 2-methylpropene, the transition state of the hydration reaction of 2-methylpropene, the aniline base and its conjugate acid, respectively. For the reaction catalyzed by nitric acid, the term $\log _{10}\left(f_{\text {alkene }} f_{\mathrm{BH}^{+}}\right) /\left(f_{\neq} f_{\mathrm{B}}\right)$ in eqn. (11) is independent of the acid concentration. It is therefore very probable that the activity coefficients of the alkene and the aniline base change relatively to the same extent as a function of the acid concentration. This is probably also true for the activity coefficients of the conjugate acid of the aniline base and the transition state of the hydration reaction. For the reaction catalyzed by 
$p$-toluenesulfonic acid, the term $\log _{10}\left(f_{\text {alkene }} f_{\mathrm{BH}^{+}}\right) /\left(f_{\ddagger} f_{\mathrm{B}}\right)$ in eqn. (11) increases with increasing acid concentration. The increase of the term which contains the activity coefficients can be explained by the relatively large salting-in effect of the $p$-toluenesulfonate ion on non-electrolytes of the Hammett indicator type [15]. This means that $\log _{10} f_{\mathrm{B}}$ decreases relative to $\log _{10} f_{\mathrm{BH}^{+}}$. The salting-in of the alkene is probably negligible because the solubility of the alkene in water is independent of the acid concentration. We checked this by measuring the solubility of cis-2-butene in water containing different amounts of $p$-toluenesulfonic acid. Cis-2-butene was used because the hydration reaction for this alkene is very much slower than for 2-methylpropene. Therefore we may conclude that the deviation from linearity between $\log _{10} k^{*}$ and $H_{0}$, based on tertiary amines, originates from a decreasing activity coefficient of the aniline base with increasing concentration of $p$-toluenesulfonic acid.

For mixtures of sulfolane and water which also show a continuous increase of the pseudo-first-order rate constant with increasing concentration of $p$-toluenesulfonic acid, unfortunately it is impossible to give a quantitative correlation between the rate constant and the acid strength as reflected by the Hammett acidity function, as no values are available for the Hammett acidity function in solutions of $p$-toluenesulfonic acid in mixtures of sulfolane and water. For reactions studied in solutions containing $89.1 \mathrm{~mol} \%$ sulfolane, it is obvious that at rather low concentrations of $p$-toluenesulfonic acid, the rate constant increases much more rapidly with increasing acid concentration than for reactions studied in water and in solutions containing $49.4 \mathrm{~mol} \%$ sulfolane.

This observation is in qualitative agreement with the results of Jussiaume et al. [9], who investigated the behaviour of the Hammett acidity function in solutions of perchloric acid in mixtures of sulfolane and water as a function of the composition of the solution. In mixtures of 1,4-dioxane and water the influence of the concentration of $p$-toluenesulfonic acid on the rate constants per equiv of acid groups is quite different from that in water and mixtures of sulfolane and water. In Fig. 4 the rate constants are plotted as a function of the acid concentration for solvent mixtures containing 39.4 and $59.8 \mathrm{~mol} \%$ 1,4-dioxane, respectively. The resulting curves show a minimum at acid concentrations of $\sim 500$ and $300 \mathrm{~mol} \mathrm{~m}^{-3}$ for mixtures containing 39.4 and $59.8 \mathrm{~mol} \%$ 1,4-dioxane, respectively. This unusual behaviour of dioxane/water mixtures does not originate from salting-out of the alkene by $p$-toluenesulfonic acid. This can be derived from the solubilities of cis-2-butene in mixtures of 1,4-dioxane and water as a function of the concentration of $p$-toluenesulfonic acid. It appears that in the region in which we have performed the kinetic experiments, the solubility of the alkene is independent of the acid concentration, within experimental accuracy. A probable explanation for this behaviour of the rate constants per equiv of acid groups as a function of the concentration of $p$-toluenesulfonic acid may be the incomplete dissociation of the acid in mixtures of 1,4dioxane and water. The degree of dissociation decreases with increasing 
mol fractions of 1,4-dioxane [17]. For concentrations below $\sim 0.5(0.3) \mathrm{kmol}$ $\mathrm{m}^{-3}$ the rate constant per equiv of acid group decreases if the acid concentration increases. This means that for acid concentrations below $\sim 0.5(0.3)$ $\mathrm{kmol} \mathrm{m} \mathrm{m}^{-3}$, a higher concentration of $p$-toluenesulfonic acid results in a lower catalytic activity per acid group because the degree of dissociation of the acid decreases if the acid concentration increases. For acid concentrations above $\sim 0.5(0.3) \mathrm{kmol} \mathrm{m}^{-3}$ the rate constant per equiv of acid groups increases if the concentration of $p$-toluenesulfonic acid increases. Above this concentration, the concentration of the $\mathrm{H}^{+}$ion and the $p$-toluenesulfonic anion are high enough for a relatively small increase of these concentrations to result in a relatively large increase of the catalytic activity per acid group. This can be explained by noting that in water, in which $p$-toluenesulfonic acid is completely dissociated, the rate constant increases more quickly with an increasing acid concentration if the acid concentration is higher.

In addition to measuring the kinetics of the hydration of 2-methylpropene catalyzed by $p$-toluenesulfonic acid, we have investigated the kinetics of this hydration reaction in the presence of poly(styrenesulfonic acid). In our experiments we used concentrations of acid groups between $\sim 0.05$ and $0.6 \mathrm{kmol} \mathrm{m}^{-3}$. In this concentration range, the rate of reaction per equiv of acid groups is independent of the concentration of acid groups within experimental error if the solvent composition is kept constant. This behaviour is different from that of $p$-toluenesulfonic acid, for which the rate of the hydration reaction per equiv of acid groups depends strongly on the concentration of acid groups.

We can explain this by assuming that two pseudo-phases coexist in the polyelectrolyte solution as proposed by Ise [18], who gave an interpretation of the results of the small angle neutron scattering (SANS) for solutions of sodium poly(styrenesulfonate) obtained by Nierlich et al. [19]. Ise proposed that the polyelectrolyte solution was composed of highly ordered clusters of macromolecules surrounded by a very dilute disordered solution of macromolecules. A change in the overall concentration of the polyelectrolyte may result in a less than proportional change in the concentration of the polyelectrolyte in each of the coexisting pseudo-phases, because it seems probable that the number and size of the ordered regions also change.

In the concentration region in which we investigated the kinetics of the hydration of 2-methylpropene, the distance between the polymer chains in the ordered regions of the solution decreases slowly with increasing concentration of the poly(styrenesulfonic acid). For sodium poly(styrenesulfonate), an increase of the concentration by a factor of 2.5 results in a decrease in the distance between the polymer chains of only $\sim 30 \%$ [18]. A slightly higher concentration of acid groups in the highly ordered regions does not result in a noticeably higher rate of the hydration reaction. This means that the catalytic activity of the acid groups in the ordered regions is virtually independent of the concentration of acid groups in the ordered regions. The reason for this is probably that in the ordered pseudo-phase the main portion of $\mathrm{H}^{+}$ions is not dissociated from the polymer chain. A slightly 
higher concentration of the macromolecules in the ordered phase has no remarkable influence on the concentration of $\mathrm{H}^{+}$ions and 'free' sulfonate anions. This results in a constant catalytic activity of the acid groups, because the catalytic activity, for example reflected by the Hammett acidity function, is more sensitive to changes in the concentration of free charges, originating from completely dissociated electrolytes, than to changes in the concentration of uncharged molecules or partly dissociated electrolytes [20]. From the results obtained so far it can be concluded that the clusters of poly(styrenesulfonic acid) molecules behave as individual micro-reactors in which the catalytic activity per equiv of acid groups is independent of the concentration of acid groups in the reaction mixture.

For mixtures of 1,4-dioxane and water and a concentration of acid groups of about $0.5 \mathrm{kmol} \mathrm{m}^{-3}$ a phase separation occurred above $\sim 35 \mathrm{~mol} \%$ 1,4-dioxane. An identical phase separation was also observed by Skerjanc and Vesnaver [21] at $45 \mathrm{~mol} \%$ 1,4-dioxane and a concentration of acid groups of $0.01 \mathrm{kmol} \mathrm{m}^{-3}$. From this it may be clear that the overall concentration of acid groups at which the highly hydrophilic ordered clusters of macromolecules can exist separately, decreases with increasing mol fraction of 1,4-dioxane.

In Tables 6 and 7 , the reaction rates and the rate constants per equivalent of acid groups are collected for mixtures of 1,4-dioxane and water and for mixtures of the sulfolane and water, respectively. For the calculation of the rate constants from the reaction rates we followed the same procedure as described for the reactions catalyzed by $p$-toluenesulfonic acid.

Qualitatively, the rate constants for the reactions catalyzed by $p$ toluenesulfonic acid and poly(styrenesulfonic acid) show a similar dependence on the mol fraction of the organic cosolvent. For mixtures of 1,4dioxane and water, the rate constants decrease continuously with increasing cosolvent concentration between 0 and 35 mol\% 1,4-dioxane. The behaviour of the rate constant at higher concentrations of 1,4-dioxane could not be investigated owing to the precipitation of the catalyst in solutions containing

\section{TABLE 6}

Reaction rates $\left(r_{\mathrm{eq}}\right)$ and rate constants $(k)$ per equiv of acid groups of the hydration of 2 -methylpropene in mixtures of 1,4-dioxane and water, catalyzed by poly(styrenesulfonic acid), at $0.1 \mathrm{MPa}$ partial pressure of 2-methylpropene and $25.0^{\circ} \mathrm{C}$

\begin{tabular}{cccc}
\hline $\begin{array}{l}\text { Mol fraction 1,4-dioxane } \\
(\%)\end{array}$ & $\begin{array}{l}10^{-1} \mathrm{~S}^{\mathrm{a}} \\
\left(\mathrm{mol} \mathrm{m}_{\mathrm{L}}^{-3}\right)\end{array}$ & $\begin{array}{l}10^{6} \mathrm{req}_{\mathrm{eq}} \\
\left(\mathrm{mol} \mathrm{eq}^{-1} \mathrm{~s}^{-1}\right)\end{array}$ & $\begin{array}{l}10^{8} \mathrm{k} \\
\left(\mathrm{m}_{\mathrm{L}} \mathrm{eq}^{-1} \mathrm{~s}^{-1}\right)\end{array}$ \\
\hline 0 & 0.50 & 2.75 & 55 \\
10.1 & 2.0 & 2.03 & 10.2 \\
20.1 & 7.5 & 1.67 & 2.23 \\
29.7 & 20 & 1.65 & 0.83 \\
35.4 & 30 & 1.81 & 0.60 \\
\hline
\end{tabular}

aThese solubilities are determined graphically with the values collected in Table 1. 
TABLE 7

Reaction rates $\left(r_{\text {eq }}\right)$ and rate constants $(k)$ per equiv of acid groups of the hydration of 2-methylpropene in mixtures of sulfolane and water, catalyzed by poly(styrenesulfonic acid), at $0.1 \mathrm{MPa}$ partial pressure of 2-methylpropene and $25.0^{\circ} \mathrm{C}$

\begin{tabular}{llcc}
\hline $\begin{array}{l}\text { Mol fraction sulfolane } \\
(\%)\end{array}$ & $\begin{array}{l}10^{-1} \mathrm{~S}^{\mathrm{a}} \\
\left(\mathrm{mol} \mathrm{m}_{\mathrm{L}}{ }^{-3}\right)\end{array}$ & $\begin{array}{l}10^{6} \mathrm{req}_{\mathrm{eq}} \\
\left(\mathrm{mol} \mathrm{eq}^{-1} \mathrm{~s}^{-1}\right)\end{array}$ & $\begin{array}{l}10^{8} k \\
\left(\mathrm{~m}_{\mathrm{L}} \mathrm{eq}^{-1} \mathrm{~s}^{-1}\right)\end{array}$ \\
\hline 0 & 0.50 & 2.75 & 55 \\
9.1 & 1.8 & 2.35 & 13 \\
20.5 & 4.7 & 2.09 & 4.4 \\
29.6 & 7.7 & 2.34 & 3.04 \\
40.7 & 11.9 & 3.05 & 2.56 \\
48.7 & 14.7 & 3.51 & 2.39 \\
60.3 & 19.6 & 4.80 & 2.45 \\
69.8 & 22.7 & 7.61 & 3.35 \\
77.3 & 25.2 & 12.1 & 4.80 \\
84.1 & 27.4 & 22.8 & 8.32 \\
88.8 & 28.6 & 52.6 & 18.4 \\
\hline
\end{tabular}

These solubilities are determined graphically with the values collected in Table 2 .

more than 35 mol\% 1,4-dioxane. For mixtures of sulfolane and water, the rate constant decreases with increasing cosolvent concentration between 0 and about $50 \mathrm{~mol} \%$ sulfolane. For both cosolvents investigated the rate constant decreases less rapidly with increasing cosolvent concentration at higher cosolvent concentrations. Above about $50 \mathrm{~mol} \%$ sulfolane the rate constant increases continuously with increasing cosolvent concentration. The rate constant increases more rapidly with increasing sulfolane concentration at higher sulfolane concentrations.

For a detailed comparison of the behaviour of the rate constants for both catalysts as a function of the concentration of the organic solvent, the ratio of the rate constants determined in the organic cosolvent/water mixtures and in water is plotted as a function of the mol fraction of the organic cosolvent. In Fig. 7 the plots for $p$-toluenesulfonic acid and poly(styrenesulfonic acid) are shown for the cosolvent 1,4-dioxane. In Fig. 8 similar plots are shown for the cosolvent sulfolane.

Figure 7 shows that the ratio of the rate constants is considerably lower for poly(styrenesulfonic acid) than for $p$-toluenesulfonic acid at the same mol fraction of the cosolvent. This can be explained by assuming that the solvent composition at the acid groups in poly(styrenesulfonic acid) is different from that at the acid groups for $p$-toluenesulfonic acid. The mol fraction of 1,4-dioxane is probably considerably lower in the polar clusters of macromolecules in the disordered pseudo-phase. This means that the concentration of 2-methylpropene in the clusters of poly(styrenesulfonic acid) molecules is lower than in the disordered region. The rate constant (per equiv of acid groups) is then higher than it would be at equal mol fractions of 1,4-dioxane in the ordered and disordered pseudo-phases. This may 

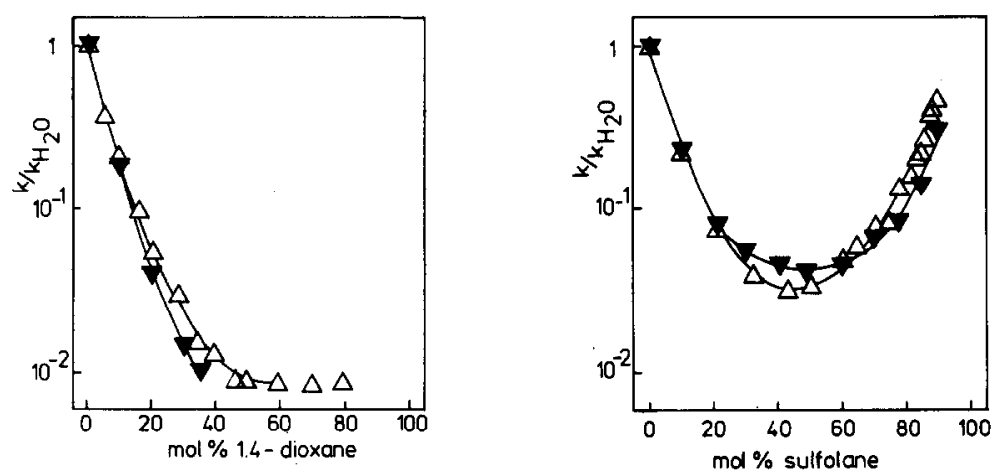

Fig. 7. Ratio of the rate constants in mixtures of 1,4-dioxane and water and the rate constant in water for the hydration of 2 -methylpropene at $25.0^{\circ} \mathrm{C}$ and catalyzed by $p$ toluenesulfonic acid $(\Delta)$ or poly(styrenesulfonic acid) $(\nabla)$.

Fig. 8. Ratio of the rate constants in mixtures of sulfolane and water and the rate constant in water for the hydration of 2 -methylpropene at $25.0^{\circ} \mathrm{C}$ and catalyzed by $p$ toluenesulfonic acid $(\triangle)$ or poly(styrenesulfonic) acid $(\nabla)$.

become clear when the rate constants of the hydration reaction catalyzed by $p$-toluenesulfonic acid are considered for mol fractions of 1,4-dioxane smaller than $50 \mathrm{~mol} \%$ (see Table 3). This effect does not compensate the influence of the lower concentration of the alkene in the clusters of poly(styrenesulfonic acid).

It appears from Tables 1 and 3 that for an overall mol fraction of 1,4dioxane of $\sim 35 \mathrm{~mol} \%$, the mol fraction of this cosolvent in the clusters of the poly(styrenesulfonic acid) molecules is not more than a few mol percent. At mol fractions of the cosolvent smaller than about $65 \mathrm{~mol} \%$, the ratio of the rate constants in sulfolane/water mixtures and in water is higher for poly(styrenesulfonic acid) than for $p$-toluenesulfonic acid at the same solvent composition (Fig. 8). At mol fractions higher than $65 \mathrm{~mol} \%$ this ratio is lower for poly(styrenesulfonic acid) than for $p$-toluenesulfonic acid. For sulfolane/water mixtures the mol fraction of the cosolvent in the ordered pseudo-phase is also expected to be lower than in the disordered region. This difference, however, is expected to be lower for sulfolane than for 1,4dioxane, due to the more polar character of sulfolane compared to 1,4dioxane. This would mean that the difference between the concentrations of the alkene in the ordered and disordered pseudo-phases is lower for sulfolane than for 1,4-dioxane. Additional to this it should be remarked, that, even if the mol fractions of 1,4-dioxane and sulfolane in the ordered pseudo-phase were the same for the same overall mol fraction of cosolvent, the difference between the concentrations of the alkene between the pseudo-phases is lower for sulfolane than for 1,4-dioxane. This follows from the solubilities of the alkene in mixtures of 1,4-dioxane or sulfolane and water (see Tables 1 and 2). For the same mol fraction of the cosolvent, the solubility of the alkene is much lower in mixtures of sulfolane and water than in mixtures of 1,4-dioxane and water. Between 0 and $\sim 65 \mathrm{~mol} \%$ sulfolane, there is a 
negative influence of the lower alkene concentration inside the clusters of poly(styrenesulfonic acid) molecules as compared to the overall alkene concentration; the overall rate constant is overwhelmed by the higher value of the rate constant inside the clusters of macromolecules as compared to its value obtained when the solvent compositions in both pseudo-phases are the same. Above $\sim 65 \mathrm{~mol} \%$ sulfolane, the values of the rate constant inside the clusters of macromolecules are not so high, or are even lower than the values expected if the solvent composition in both pseudo-phases were the same. This results in a lower ratio of the rate constants in sulfolane/water mixtures and in water for poly(styrenesulfonic acid) than for $p$-toluenesulfonic acid. From Table 4 and Fig. 8, it may become clear that for $\sim 65 \mathrm{~mol} \%$ sulfolane the mol fraction of the cosolvent in the ordered pseudo-phase is probably not higher than $\sim 20 \%$.

In the discussions above, it is assumed that the influence of the solvent composition in the immediate neighbourhood of the acid groups on the catalytic activity of these groups is the same for both catalysts investigated.

The behaviour of the clusters of poly(styrenesulfonic acid) molecules in binary mixtures of water and an organic solvent closely resembles the behaviour of gel-type strong acid ion-exchange resins, composed of sulfonated copolymers of styrene and divinylbenzene. This resemblance is clarified in the review of Moody and Thomas [22], who summarized the results of the investigations of the behaviour of strong acid ion-exchange resins in binary mixtures of organic solvents and water. From this review, it appears that for a fixed mol fraction of the organic solvent in the free liquid, the mol fraction of the organic cosolvent in the pores of the ion-exchange resin decreases with decreasing dielectric constant of the cosolvent.

\section{Conclusion}

From the results described in this paper we can conclude that, although the solubility of 2-methylpropene in mixtures of 1,4-dioxane and water is higher than in mixtures of sulfolane and water, the cosolvent sulfolane is probably more convenient than 1,4-dioxane for an increase of the rate of the hydration of lower alkenes catalyzed by strong acid ion-exchange resins. The positive influence of the cosolvent is probably most pronounced for mol fractions of sulfolane higher than $80 \mathrm{~mol} \%$.

It is clear that a sounder choice of the most convenient cosolvent requires experimental data on the influence of solvent on the kinetics of the hydration reaction catalyzed by strong acid ion-exchange resins. In a following paper, we describe the results of a study of the influence of the solvent composition on the kinetics of the hydration of 2-methylpropene catalyzed by some types of strong acid ion-exchange resins [23]. In that paper we also give a quantitative description of the solvent composition in the pores of the resin as a function of the mol fraction of the cosolvent in the surrounding liquid. 


\section{References}

1 W. Neier and J. Wöllner, Hydrocarbon Process., November (1972) 113.

2 W. Neier and J. Wöllner, Chemtech, 3 (1973) 95.

3 L. Petrus, R. W. de Roo, E. J. Stamhuis and G. E. H. Joosten, Chem. Eng. Sci., 41 (1986) 217.

4 L. Petrus, Ph.D. Thesis, University of Groningen, 1982, Chapt. 8.

5 L. Petrus, Ph.D. Thesis, University of Groningen, 1982, Chapt. 6.

6 V. J. Nowlan and T. T. Tidwell, Acc. Chem. Res., 10 (1977) 252.

7 W. K. Chwang, V. J. Nowlan and T. T. Tidwell, J. Am. Chem. Soc., 99 (1977) 7233.

8 R. H. Boyd, in J. F. Coetzee and C. Ritchie (eds.), Solute-Solvent Interactions, Marcel Dekker, New York, 1969, p. 163.

9 A. Jussiaume, M. Godel and F. Coussement, J. Chim. Phys. Physicochim. Biol., 68 (1971) 1315.

10 M. H. Abraham, Progr. Phys. Org. Chem., 11 (1974) 1.

11 E. Buncel and H. Wilson, Acc. Chem. Res., 12 (1979) 42.

12 A. Streitwieser, Jr. and C. H. Heathcock, Introduction to Organic Chemistry, Macmillan, New York, 1976, p. 279.

13 C. F. Wells, J. Chem. Soc., Faraday Trans 1, (1978) 1569.

14 R. W. Taft, Jr., J. Am. Chem. Soc., 74 (1952) 5372.

15 E. M. Arnett and G. W. Mach, J. Am. Chem. Soc., 88 (1966) 1177.

16 K. Wiberg, Physical Organic Chemistry, Wiley, New York, 1964, p. 436.

17 C. S. Baker and H. A. Strobel, J. Phys. Chem., 83 (1979) 728.

18 N. Ise, Makromol. Chem., Suppl. 5 (1981) 107.

19 M. Nierlich, C. E. Williams, F. Boue, J. P. Cotton, M. Daoud, B. Farnoux, G. Jannink, C. Picol, M. Moan, C. Wolf, M. Rinaudo and P. G. de Gennes, J. Phys. (Paris), 40 (1979) 701 and references therein.

20 J. E. Gordon, The Organic Chemistry of Electrolyte Solutions, in G. A. Olah (ed.), Interscience Monographs on Organic Chemistry, Wiley, New York, 1975, Chapt. 1.

$21 \mathrm{~J}$. Skerjanc and G. Vesnaver, Macromolecules, 16 (1983) 1164.

22 G. J. Moody and J. D. R. Thomas, Analyst, 93 (1968) 55.

23 J. Meuldijk, G. E. H. Joosten and E. J. Stamhuis, J. Mol. Catal, submitted for publication. 